\title{
Analysis of sentinel-1 data for regional crop classification: a multi-data approach for rabi crops of district Hisar (Haryana)
}

\author{
Isha Ahlawat * \\ Department of Agronomy, College of Agriculture, Chaudhary Charan Singh Haryana Agri- \\ cultural University, Hisar-125004 (Haryana), India \\ Hardeep Singh Sheoran \\ Department of Soil Science, College of Agriculture, Chaudhary Charan Singh Haryana \\ Agricultural University, Hisar-125004 (Haryana), India \\ Roohi \\ Department of Soil Science, College of Agriculture, Chaudhary Charan Singh Haryana \\ Agricultural University, Hisar-125004 (Haryana), India \\ Garima Dahiya \\ Department of Soil Science, College of Agriculture, Chaudhary Charan Singh Haryana \\ Agricultural University, Hisar-125004 (Haryana), India \\ Parveen Sihag \\ Haryana Space Applications Centre, Chaudhary Charan Singh Haryana Agricultural \\ University, Campus, Hisar-125004 (Haryana), India
}

Corresponding author: E-mail: isha3214@gmail.com

\begin{abstract}
Generation of spatio-temporal information such as land use system and management practices is one of the key ingredients for carrying out the regional level agro-ecosystem modelling. However, at the regional level availability of such data is scarce, where analysis of a cropping system is essential and a pre-requisite for studying the overall sustainability of the agricultural production system. The present investigation was carried out to identify the actually practised cropping pattern and their mapping in Hisar district of Haryana (India) using Multi-Data Approach (MDA). Multi-date sentinel-1 for the rabi season of 2019 was classified using multi-phase unsupervised classification approach and classes of interest were identified. Finally, classified images were subjected to logical combinations which helped in generating crop classification maps and statistics. Results showed that cropping pattern of the district exhibited huge variations and area under wheat was observed to be highest (204.76 thousand ha) in comparison to mustard crop (64.42 thousand ha) and least was under the sugarcane crop (0.97 thousand ha). Some other crops like vegetables and horticultural crops were also identified during this period, but the major crops that were identified during rabi 2019 were wheat and mustard. Hence, regional crop classification using sentinel-1 data appears to be a valuable tool for predicting a specific regions cropping pattern, which is considered to be the most significant aspect of an agricultural production system.
\end{abstract}

Keywords: Crop classification, Mapping, Multi-data approach, Remote sensing, Sentinel-1

\section{Article Info}

https://doi.org/10.31018/

jans.vi.2263

Received: April 28, 2020

Revised: May 16, 2020

Accepted: May 25, 2020

\section{How to Cite}

Isha, A. et al. (2020). Analysis of sentinel-1 data for regional crop classification: a multi-data approach for rabi crops of district Hisar (Haryana). Journal of $A p$ plied and Natural Science, 12(2): 165 - 170.

https://doi.org/10.31018/ jans.vi.2263

\section{INTRODUCTION}

The major challenge for Indian agriculture in the coming era will be to meet the ever increasing demands for food, fibre and energy while maintaining or sustaining natural resources (Gopalasundaram et al., 2012) and it is anticipated that further increase in production and productivity would only be possible through intensive use of land resources, irrigation, fertilizers, pesticides, modern machineries and advanced techniques (Lopes et al., 2011). Various schemes such as crop insurance, per drop more crop, Rashtriya Krishi Vikas Yojna were launched by Government of India to enhance the production and productivity of the crops, and however, in order to implement these programs effectively, it is vital to use the latest technologies like remote sensing and GIS which are capable of identifying the potential of land for any particular crop or cropping system. Innovative practices like organic farming significantly enhance the soil organic carbon and its stocks in soils (Sheoran et al., 2018) which ultimately decide the productivity of particular agricultural systems can also be monitored regularly using advanced GIS technologies. GIS is the best technique as it brings all the data on a 
Isha, A. et al. / J. Appl. \& Nat. Sci. 12(2): 165 - 170 (2020)

single platform for the analysis where natural inputs in farming cannot be measured but, can be better understood and managed with GIS applications which primarily includes cropping pattern and yield estimates (Blackmore et al., 2003; Bramley, 2009), soil amendment analysis, erosion identification and remediation (Casa et al., 2011) and water content estimation (Delin and Berglund, 2005). The decision-makers can visualize all the farmlands with their allied information and current situation on one click. The tasks like cropping pattern analysis, yield estimation and crop damage assessment done by traditional means take a month or two and as a whole requires a lot of manpower to complete the work, whereas by using recent technologies like remote sensing and GIS the same task can be completed within half or even in the lesser time frame with a minimum number of resources and high accuracy. The ability of GIS to study and envisage agricultural environment and workflows has proved to be favourable to those involved in the farming community. Remote sensing can provide data that helps to identify and monitor the crops and when this data is organized in GIS along with other parameters, they become an important tool that helps in making decisions about crops and agricultural strategies (Bhatta, 2008). Government authorities or local agencies can use remote sensing data in order to make critical decisions about the policies that can be adopted or measures to tackle national issues regarding agriculture. Different vegetation indices like NDVI, FPAR and TVI are widely used to monitor crop health which is directly proportional to yield (Wang et al., 2009). In the case of crop insurance, actual damage can be assessed easily and hence, claims and compensations can be given timely and in the right amount. Hence, remote sensing is the need of the hour to introduce latest technologies in agriculture and to enhance its production, which helps the decision makers to take quick and robust decisions. Thus, we can conclude that geoinformatics has opened up new vistas in generating real time information pertaining to various fields. The ability of space platforms to provide synoptic view of the area makes remote sensing a unique tool for rapid and timely monitoring of earth resources (Singh et al., 2019). Keeping in view the above concerns, the present study was planned with the objective to identify the actually practised cropping systems and their mapping in Hisar district of Haryana (India) using the multi spatio-temporal data through Multi-Data Approach (MDA).

\section{MATERIALS AND METHODS}

Study area: Hisar is located at $29.09^{\circ} \mathrm{N}$ and $75.43^{\circ} \mathrm{E}$ in western Haryana with an average elevation of $215 \mathrm{~m}$ above mean sea level. It is a part of the alluvial Ghaggar-Yamuna plain and its southern and western portions mark a gradual transition to the desert. Hisar is having very hot summers and relatively cool winters with extremes of temperature and scanty rainfall. The average annual rainfall is about $429 \mathrm{~mm}$, which generally occurs during July to September.

Satellite data: Remote sensing data is the basic data source for mapping the cropping pattern of the Hisar district. The Sentinel-1 data was downloaded using earth explorer open access hub (https://earthexplorer.usgs.gov), which is an ideal one with an optimum spatial resolution of $5 \times 5 \mathrm{~m}$. Its repeat cycle was used deriving the regional crop classification of rabi- 2019. Temporal sentinel-1 data was acquired for sugarcane, mustard and wheat crop on 16th November 2019, 25th January and 12th February 2020, respectively. The boundary of Hisar district was overplayed on the satellite image and all the data elements (pixels) within this were extracted for further analysis. Multi-layer stacks were prepared for rabi-2019 using multidate images. Images were classified using a multiphase unsupervised classification approach using Iterative Self-organizing Data Analysis Technique (ISODATA) clustering classifier and classes of interest were identified. Finally, classified images subjected to logical combinations which helped in generating crop classification maps and statistics (Arvind et al., 2020).

\section{RESULTS AND DISCUSSION}

Spatial distribution of crops in the study area showed large spatial and temporal variations during growing rabi season of the year 2019. Sowing of rabi crops in Haryana mainly takes place during October to December and can even go up to January and harvested from March to April every year. In season, multi-date sentinel-1 data was used to estimate the regional crop classification area of the Hisar district. Classified images along with satellite images as background, where different colours indicate the area under different crops during the rabi season 2019 have been shown in Fig. 1 to 10 .

The block-wise area statistics derived from sentinel-1 data (Table 1) suggested that the total area was observed to be 17.12 thousand hectares under wheat for Adampur block of the district. Further, the calculated area of the block suggested that mustard crop alone contributes about 14.48 thousand ha. The extent of fallow land/ other crops has been estimated to be high (5.58 thousand ha) which was much higher than the sugarcane crop ( 0.005 thousand ha) during the rabi season 2019. Spatial distribution maps of rabi crops in the study area are depicted in Fig. 1. While area under wheat in case of Agroha block was observed to be 17.48 thousand ha, this was higher than area under mustard (8.76 thousand ha) during 2019. Moreover, the area was ob- 
Isha, A. et al. / J. Appl. \& Nat. Sci. 12(2): 165 - 170 (2020)

Table 1. Blockwise area under different crops in Hisar district during Rabi-2019 season.

\begin{tabular}{clcccc}
\hline \multirow{2}{*}{ Sr. No. } & Block & Wheat & Mustard & Sugarcane & $\begin{array}{c}\text { Fallow land/ other } \\
\text { crops }\end{array}$ \\
\cline { 3 - 6 } & & 17.12 & 14.48 & 0.01 & 5.58 \\
2 & Adampur & 17.48 & 8.76 & 0.01 & 3.27 \\
3 & Agroha & 29.56 & 8.22 & 0.15 & 7.28 \\
4 & Barwala & 34.81 & 7.42 & 0.1 & 9.14 \\
5 & Hansi-I & 17.27 & 0.8 & 0.5 & 0.89 \\
6 & Hansi-II & 27.19 & 8.14 & 0.01 & 13.63 \\
7 & Hisar-I & 17.57 & 10.32 & 0.01 & 21.77 \\
8 & Narnaund & 30.32 & 3.56 & 0.18 & 3.44 \\
9 & Uklana & 13.47 & 2.72 & 0 & 4.04 \\
& Total & $\mathbf{2 0 4 . 7 9}$ & $\mathbf{6 4 . 4 2}$ & $\mathbf{0 . 9 7}$ & $\mathbf{6 9 . 0 5}$ \\
\hline
\end{tabular}

served to be higher (17.48 thousand ha) under fallow land or other crops category than sugarcane crop ( 0.006 thousand ha) in the study area. Some of the area under fallow land category was also found to belong to the wheat crop, however, due to lower value of LAl it seems to appear fallow on the satellite image. Spatial distribution maps of rabi crops in the study area are depicted in Fig. 2.

Based on the data, the block-wise trend of area estimates of Barwala block for crop classification showed that the major area was recorded under wheat (29.56 thousand ha), mustard (7.42 thousand ha) and fallow land (7.28 thousand ha), respectively. While in case of area under sugarcane ( 0.15 thousand ha), scattered patches over the entire area were observed. Spatial distribution map of crops is also depicted in Fig. 3. Data on agricultural crop classification in Hansi-I block of Hisar district of Haryana revealed that among all the locations, the area under wheat crop was observed to be highest ( 34.08 thousand ha). Moreover, it was observed that the area under mustard crop was 7.42 thousand ha for the current season. The area estimates based on the available satellite data showed that 9.14 thousand ha area was recorded for the fallow land in the block while it was 0.10 thousand ha area in case of sugarcane crop. Variations in rabi crops in the study area are also presented in Fig. 4. Moreover, the figures of the area under different crops revealed that wheat area recorded in Hansi-II block was 17.27 thousand ha. The fallow land was 0.89 thousand ha whereas mustard crop holds only 0.80 thousand ha area whereas sugarcane constitutes about 0.51 ha area. Regional crop classification is also depicted in a classified image of the block (Fig. 5). Area estimation for Hisar-I block demonstrated that no significant variation exists and similar cropping pattern was observed for the block. The data showed that about 27.18 thousand ha area came under wheat crop while only 8.14 thousand ha area was observed to be under mustard crop. A similar pattern to other blocks of the study area was observed for sugarcane (0.01 thousand ha) and fallow land category (13.63 thousand ha). Crop classification pattern is presented in Fig. 6. Similarly, for Hisar-Il block of Hisar, the wheat area was observed to be significantly higher (17.57 thousand ha) than other crops. Similarly, mustard during rabi season secured second highest value (10.32 thousand ha) while lowest was observed in case of sugarcane which accounts only 0.014 thousand ha area and represents an only small portion of the total cultivated land. Crop classification pattern for the block is presented in Fig. 7.

Analysis of remote sensing data for Narnaund block showed that the total area under wheat was observed to be 30.32 thousand ha during rabi season 2019, which represent a maximum cropped area of the total area. Similarly, 3.56 thousand ha area under mustard crop, 0.18 thousand ha under sugarcane and 3.44 thousand ha under fallow land/ other crops category of the total cropped area was recorded (Table 8 ). Major rabi crops for Narnaund block are also depicted in Fig. 8, which are derived from multi-date sentinel-1 data while wheat is evenly spread throughout the study area where the area under mustard crop and fallow land is less in Uklana block of the district (Table 1). The maximum area of 13.47 thousand ha was recorded for wheat followed by fallow land or other crops with an area of 4.03 thousand ha while the minimum area, i.e. 2.72 thousand ha was under mustard crop. The results from multi-date sentinel-1 data showed that the cropping pattern being followed for the other blocks of the district was also practised in this block. Major rabi crops in the study area are also depicted in Fig. 9. Overall, it was observed that wheat and mustard are the dominating crops in all the blocks of the district and very less area or negligible area was observed to be under sugarcane crop.

The area estimates for different crops for Hisar district based on the available multi-date sentinel-1 satellite data is presented in Fig. 10. The regional crop classification showed large spatial and temporal variation during growing rabi season of the year 2019. It was observed from the results that cropping pattern of the district exhibited huge vari- 
Isha, A. et al. / J. Appl. \& Nat. Sci. 12(2): 165 - 170 (2020)

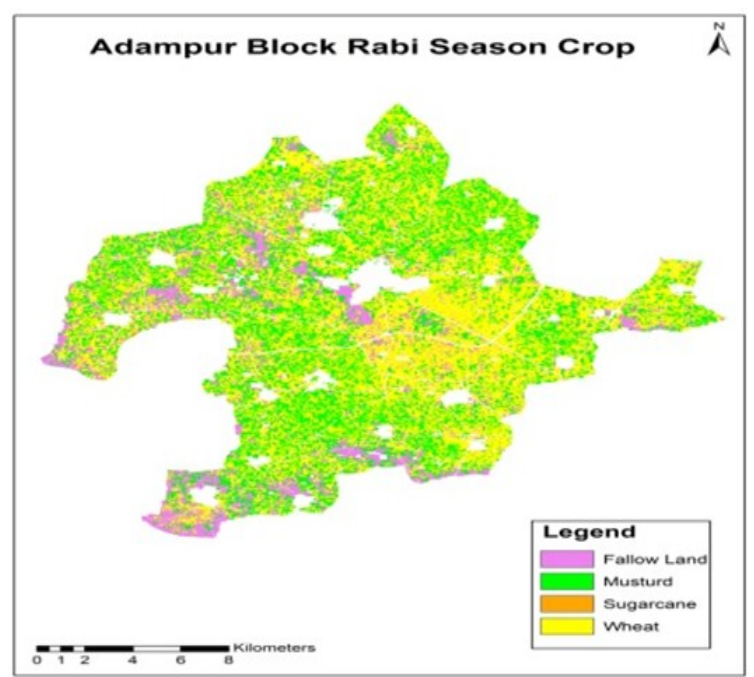

Fig. 1: Cropping pattern of Adampur block of Hisar District during rabi season- 2019.

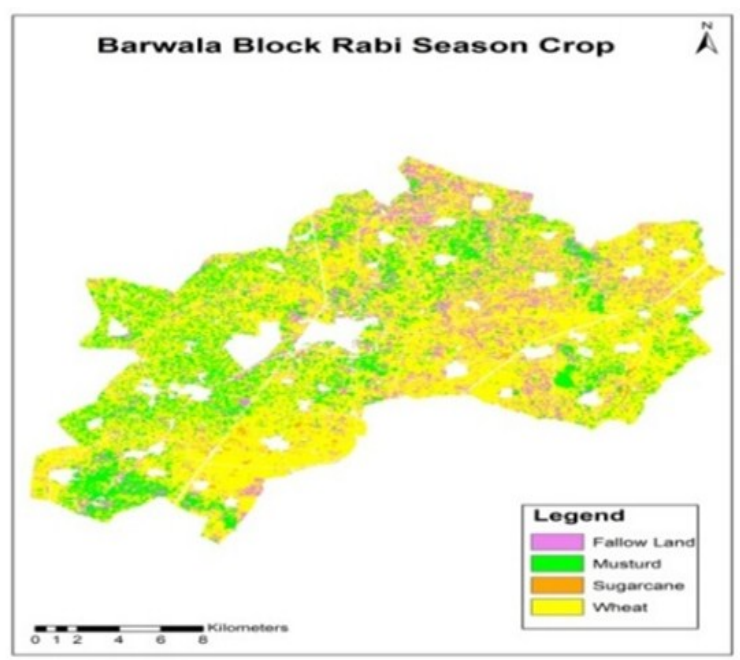

Fig. 3: Cropping pattern of Barwala block of Hisar District during rabi season- 2019.

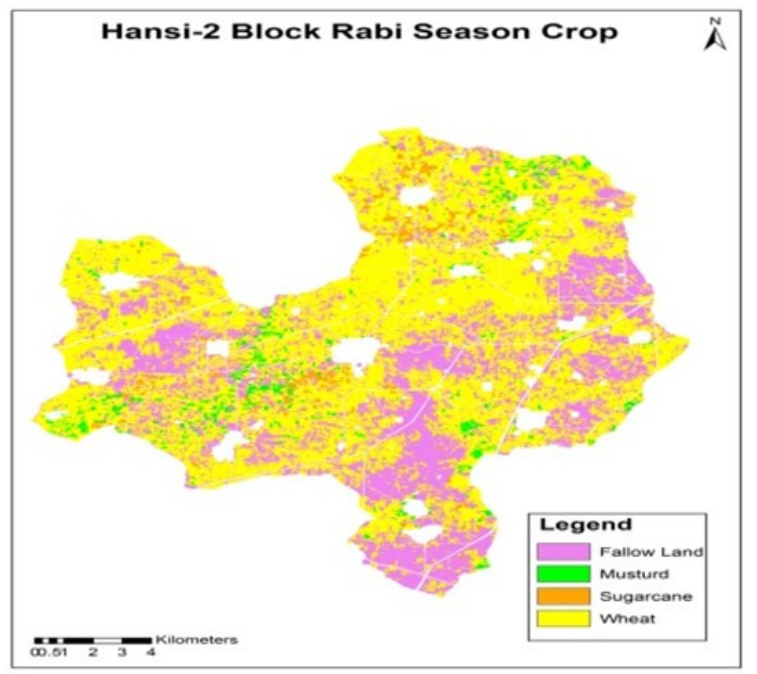

Fig. 5: Cropping pattern of Hansi-2 block of Hisar District during rabi season- 2019.

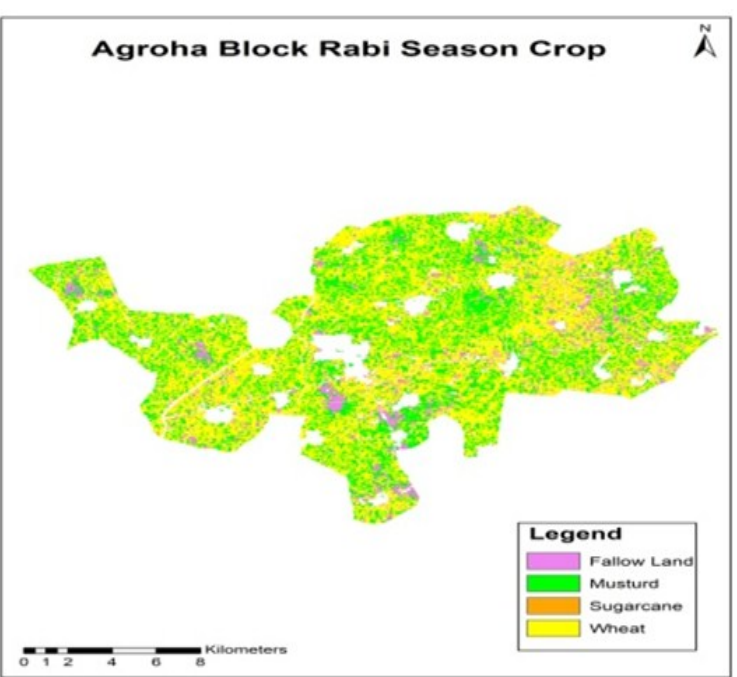

Fig. 2: Cropping pattern of Agroha block of Hisar District during rabi season- 2019.

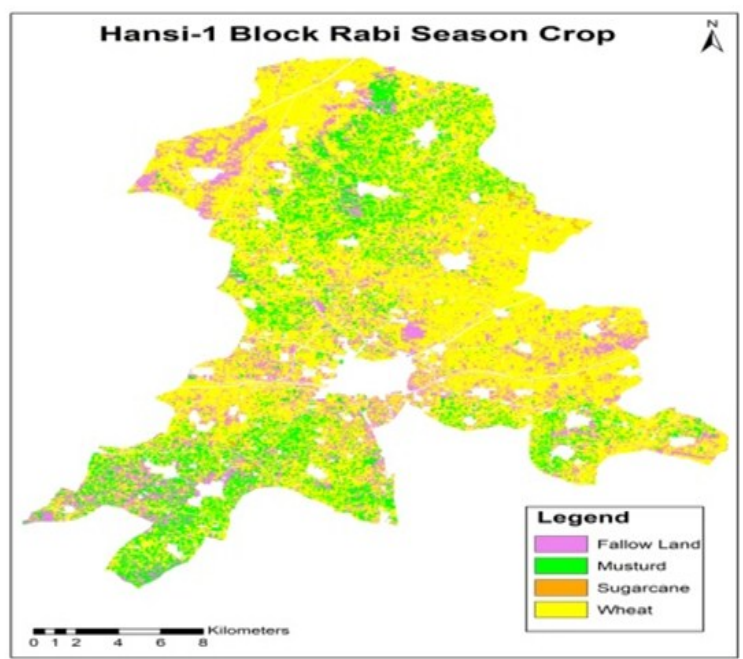

Fig. 4: Cropping pattern of Hansi-1 block of Hisar District during rabi season- 2019.



Fig. 6: Cropping pattern of Hisar-1 block of Hisar District during rabi season- 2019. 
Isha, A. et al. / J. Appl. \& Nat. Sci. 12(2): 165 - 170 (2020)

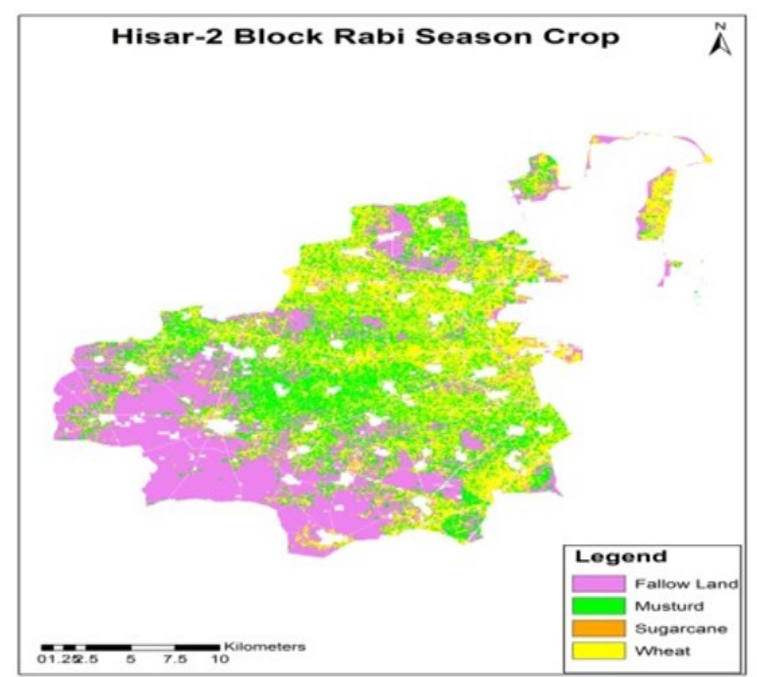

Fig. 7: Cropping pattern of Hisar-2 block of Hisar District during rabi season- 2019.

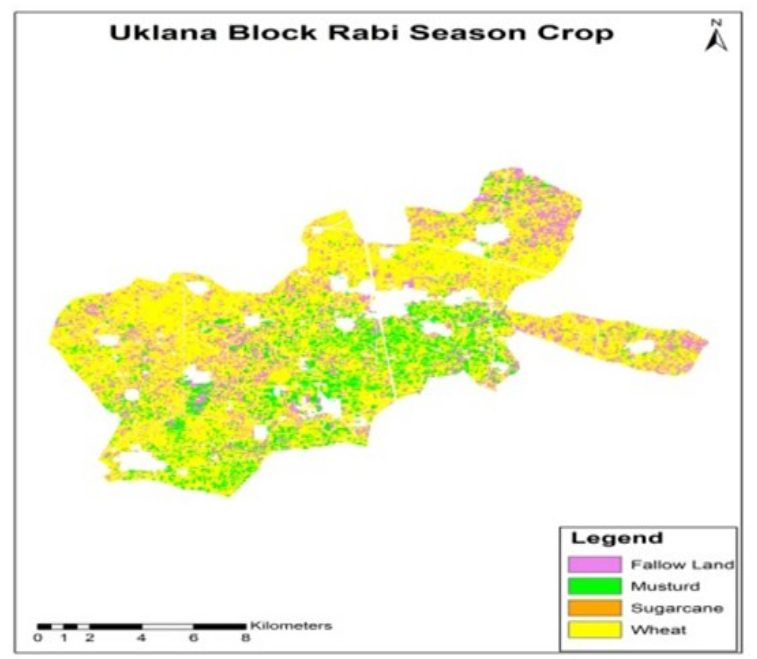

Fig. 9: Cropping pattern of Uklana block of Hisar District during rabi season- 2019 .

ations at different locations and the major crops identified in the study area were wheat, mustard and sugarcane. The area under wheat was observed to be highest (204.76 thousand ha) in comparison to the proximity mustard crop (64.42 thousand ha) and least was under the sugarcane crop ( 0.97 thousand ha). Some other vegetables and horticultural crops were also identified during this period, but the major crops that were identified during rabi 2019 season were wheat and mustard. However, some of the area under fallow land category was also supposed to belong to wheat but due to low value of LAl it seems to appear fallow on a satellite image. Similar findings were also reported by Arvind et al. (2020) studied the cropping pattern of Barwala sub branch of Sirsa branch of Western Yamuna Canal in Haryana and reported the appropriateness of remote sensing techniques for mapping crop types and



Fig. 8: Cropping pattern of Narnaund block of Hisar District during rabi season- 2019.

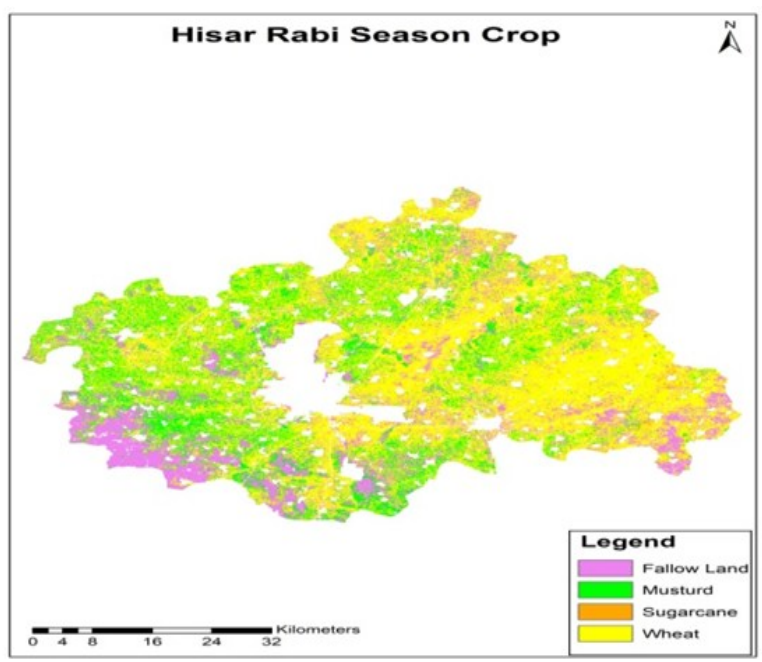

Fig. 10: Cropping pattern of Hisar District of rabi season- 2019.

area using satellite data. He observed wheat and mustard as major crops in the rabi season. Other crops, including vegetables, fodder, guar, gram, etc. were also demarcated in both seasons. Moreover, since the Rice-Wheat cropping system is commonly practised on a large scale (of about 9.6 $\times 10^{6}$ ha area in India) (Badarinath et al., 2006) and this could be the possible reason for the maximum area under wheat during the rabi season as compared to the other crops. In another study, Satyawan et al. (2014) carried out the cropping system analysis of Sirsa District, Haryana and reported wheat and mustard as dominating crop during rabi season and finds geo-spatial approach as a suitable strategy in analysis of the cropping system. Adampur, Agroha and Hisar-2 blocks of Hisar is a dry belt (less moisture availability) and mustard area under these blocks is high as compared to wheat because mustard crop grows well 
under low moisture availability conditions. Ricewheat cropping system is mainly followed in Hansi block. In this block, due to the presence of heavy textured soils, the area under wheat and sugarcane is more in comparison to mustard.

\section{Conclusion}

Analysis of the cropping pattern of the district exhibited huge variations and area under wheat was observed to be highest followed by mustard crop, whereas the least area was observed under the sugarcane crop. Some other crops like vegetables and horticultural crops were also identified during this period, but the major crops that were identified during rabi 2019 were wheat and mustard. Therefore, geo-spatial techniques appear to be a suitable strategy in predicting a regional crop classification using sentinel-1 data, which is considered to be the most significant aspect of an agricultural production system.

\section{REFERENCES}

1. Arvind, Hooda, R.S., Sheoran, H.S., Kumar, D., Satyawan, A. and Bhardwaj S. (2020). RS based regional crop identification and mapping: $A$ case study of Barwala sub-branch of Western Yamuna Canal in Haryana (India). Indian Journal of Traditional Knowledge,19 (1): 182-186.

2. Badarinath, K.V.S., Kiran Chand, T.R., Prasad and K.V. (2006). Agriculture crop residue burning in IndoGangetic Plains - A study using IRS-P6 AWiFS satellite data. Current Science,91(8): 1085-1089.

3. Bhatta, B. (2008). Remote Sensing and GIS, Oxford University Press.

4. Blackmore, S., Godwin, R.J. and Fountas, S. (2003). The analysis of spatial and temporal trends in yield map data over six years. Biosystems Engineering, 84 (4): 455-466. doi:10.1016/S1537-5110(03)00038-2.

5. Bramley, R.G.V. (2009). Lessons from nearly 20 years of Precision Agriculture research, development, and adoption as a guide to its appropriate ap- plication. Crop and Pasture Science,60: 197- 217. doi:10.1071/CP08304.

6. Casa, R., Cavalieri, A. and Lo Cascio, B. (2011). Nitrogen fertilization management in precision agriculture: A preliminary application example on maize. Italian Journal of Agronomy, 6(e5): 23-27. doi:10.4081/ija.2011.e5.

7. Delin, S. and Berglund, K. (2005). Management zones classified with respect to drought and waterlogging. Precision Agriculture, 6: 321- 340. doi:10.1007/s11119-005-2325-4.

8. Gopalasundaram, P., Bhaskaran A. andRakkiyappan, P. (2012). Integrated nutrient management in sugarcane.Sugar Tech,14: 3-20. doi:10.1007/s12355-0110097-x.

9. Lopes, H.L., Candeias, A.L.B., Accioly, L.J.O., Sobral, M. doC. M. and Pacheco, A.P. (2010). Parametros biofísicos na detecçao de mudanças na cobertura e uso do solo em bacias hidrograficas. Revista Brasileira de Engenharia Agrícola e Ambiental, 14 (11): 1210-1219. doi:10.1590/S141543662010001100011.

10.Satyawan, Yadav, M. and Hooda, R.S. (2014). Cropping system analysis using Geospatial Approach: A case study of Sirsa district in Haryana, India.International Journal of Science and Research, 3 (9): 113-132.

11.Sheoran, H.S., Phogat, V.K., Dahiya, R. andKakar, R. (2018). Soil organic carbon stocks and carbon dynamics under organic and conventional farming systems in Indo-Gangetic Plains. Indian Journal of Agricultural Science, 89 (5): 813-20.

12.Singh, J., Mahapatra, A., Basu, S. and Banerjee, B. (2019). Assessment of Sentinel-1 and Sentinel-2 Satellite Imagery for Crop Classification in Indian Region During Kharif and Rabi Crop Cycles. International Geoscience and Remote Sensing Symposium, Yokohama, Japan, 3720-3723. doi:10.1109/ IGARSS.2019.8900491.

13.Wang, M., Son, S. and Shi, W. (2009). Evaluation of MODIS SWIR and NIR-SWIR atmospheric correction algorithms using SeaBASS data. Remote Sensing of Environment, 113(3): 635-644. doi:10.1016/ j.rse.2008.11.005. 